\title{
هل يمكن للقلق أن يؤدي إلى الخرف؟
}

نور شاهين

noor rafiq2006@hotmail.com

تتير نتائج دراسة حديثة إلى أن القلق المستمر -متوسط الثدة إلى الثديد- في منتصف العمر ، قدؤدي إلى الخرف في السنوات اللاحقة، وإلى تسارع التراجع المعرفي عند المرضى.

أجرى فريق من العلماء بحثًا بإنشراف الباحثة "إيمي جيمسون Amy Gimson"، من كلية الطب بجامعة "ساوثامبتون Southampton" في المملكة المتحدة، لاحظت فيه "جيمسون" وزملاؤها أن هناك دراسات كثيرة

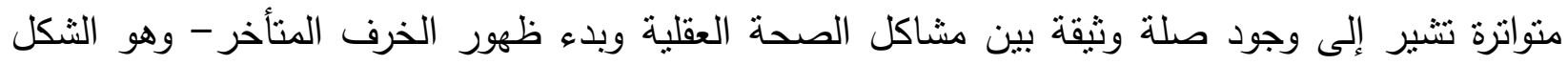

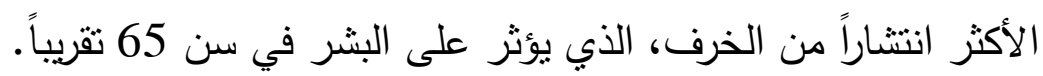

غالباً ما يرتبط القلق بالاكتئاب، وكثيراً ما يتم سرد أعراض القلق قبل سنوات من نشخيص الخرف لدى المرضى. ولكن لم يتضح بعد إذا ما كانت تللك الارتباطات تعني أن القلق والاكتئاب هما أعراض أولية للخرف الكامل، أو أنهما عوامل خطر مستقلة.

وللتحقق من ذلك، حلت "جيمسون" وفريقها ما يقارب 3500 دراسة، تحليلاً رُجُوعيًا'، بحثًا عن الأوراق التي تحرّت العلاقة بين الاكتئاب في منتصف العمر، مع أو بدون قلق، وبين ظهور الخرف المتأخر • ونشرت

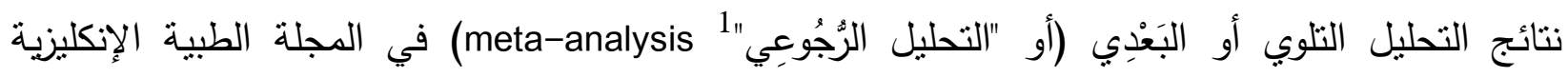
المفتوحة ("بي إم جي" BMJ Open).

القلق - عامل خطر للخرف

من بين مجموعة الأبحاث التي تم تحليلها، كانت هناك أربع دراسات فقط متحورة حول الموضوع المطلوب،

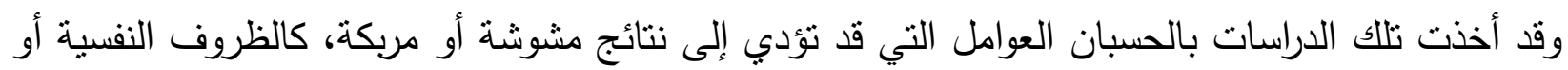

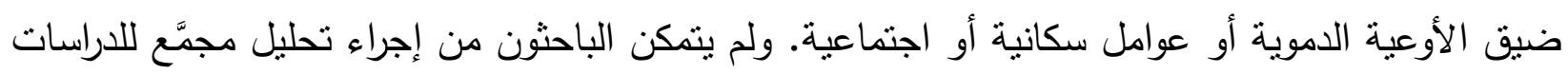
الأربع، لأنها كانت منباينة في التصميم، ولكن الطرق المستخدمة فيها كانت موثوقة ونتائجها قوية، كما يؤكد

إلى درأ ${ }^{1}$

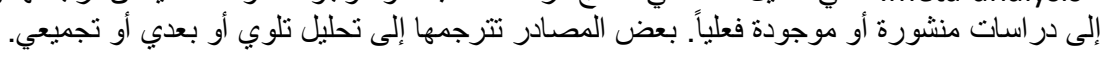


المؤلفون. زد على ذللك، فإن حجم العينات المشمولة في الدراسات الأربع كان كبيرًا للغاية، بما يقارب ثلاثين ألف (30,000) شخصاً.

وجد الباحثون أن الدراسات الأربع تؤكد على وجود علاقة طردية بين القلق منوسط الثدة إلى الثديد وبين

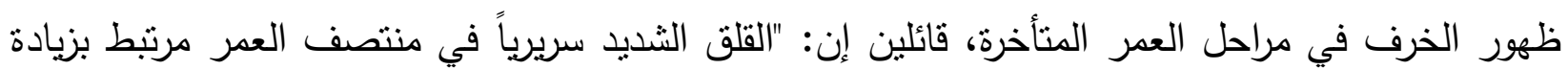
خطر الإصابة بالخرف خلال فترة لا تقل عن 10 سنوات".

وتشير النتائج إلى أن القلق قد يكون عامل خطر مستقل لظهور الخرف المتأخر، باستثناء القلق الذي قد يمثل أحد الأعراض الأولية للخرف. ويمكن تفسير الصلة بين القلق والخرف من خلال الاستجابة المفرطة للضغوط الناجمة عن الظروف الصحية النفسية.

\section{تخفيف القلق قـ يمنع الخرف}

إذا كان رد الفعل المتوتز، الناجم عن القلق، سبباً في الانخفاض السريع للقدرة المعرفية والإدراكية، فهل يعني

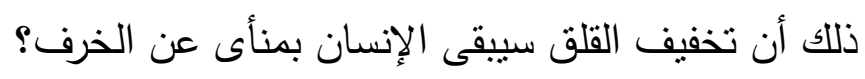

على الرغم من أن هذا السؤال ييقى مفتوحاً، إلا أن المؤلفين يشيرون إلى أن العلاجات المضادة للقلق - غير

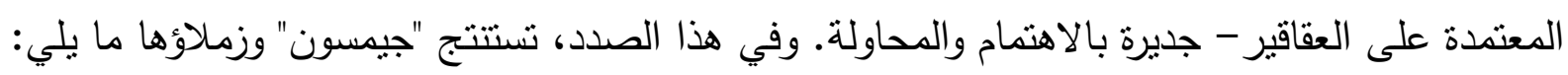
"إن العلاجات غير الدوائية، بما في ذللك العلاجات التي تعتمد على الحوار والمداخلات التي تركز على الوعي الكامل والتأمل، المعروفة بخفض القلق في فترة منتصف العمر، يمكن أن تقلل من مخاطر القلق والخرف، علماً أن ذلك يحتاج إلى دراسات معدقة وشاملة". 